
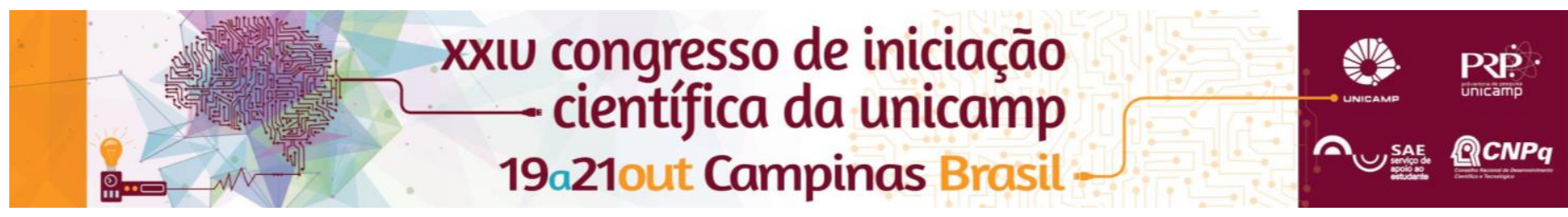

\title{
Software Analisador de Formas Geométricas de Partículas Sólidas
}

\author{
Nelson C. S. Neto*, Katia Tannous
}

\section{Resumo}

O software APOGEO é um programa de caracterização de partículas geométricas sólidas. Neste trabalho, realizou-se uma breve revisão bibliográfica sobre caracterização de partículas sólidas, linguagem computacional Java, testes de compatibilidade, pré-tratamento de imagem. Além disso, um canvas foi avaliado para comercialização do software.

\section{Palavras-chave:}

Partícula sólida, Linguaguem Java, Processamento de imagem.

\section{Introdução}

Durante a fase de modelagem e seleção dos equipamentos em processos industriais, o conhecimento das características físicas do material a ser processado é de suma importância para a qualidade do produto final[1].

O software APOGEO[2] auxilia na verificação das dimensões e geometrias de partículas sólidas (paralelepípedo, cilíndrica, esferoides, irregular), aliado a uma interface amigável e simples, permitindo ao usuário estabelecer padrões de leitura de imagens, remoção de imperfeições da imagem e seleção de partícula de interesse. Como resultado obtém a esfericidade das amostras mediante equações empíricas (Wadell, Curray, Riley, Massarani e Peçanha).

O objetivo deste trabalho foi analisar a compatibilidade em diferentes sistemas operacionais, criação de um padrão de imagem para garantir bons resultados, adição de novas formas geométricas no banco de dados. Além disso, um Canvas foi avaliado para comercialização do software.

\section{Resultados e Discussão}

Primeiramente, foi realizado testes de compatibilidade para o sistema operacional Windows, contemplando diferentes versões (windows XP, 7, Vista e 8) para arquitetura 32 e 64 bits. Em todas as plataformas testadas o software funcionou corretamente.

Com relação ao processamento digital, esta pode ficar comprometida pela falta de combinação de cores da partícula e do fundo da imagem (Figura 1).

Dessa forma, foi criado um padrão na qualidade das imagens utilizando o software Shutterfly Studio com uma simples alteração de brilho e contraste. A Tabela 1 mostra as simulações realizadas partir da imagem original, onde a condição, brilho e contraste suaves, exibiu o melhor resultado com 51 partículas. Estes testes também foram aplicados para fundo distintos (branco ou preto) em função da coloração das partículas.

Tabela 1: Pré-tratamento das imagens de 50 partículas

\begin{tabular}{|c|c|c|c|}
\hline Imagem & Brilho & Contraste & $\begin{array}{c}\text { Node } \\
\text { Partículas }\end{array}$ \\
\hline Original & 0 & 0 & 256 \\
\hline $\begin{array}{c}\text { Brilho suave } \\
\text { Contraste suave }\end{array}$ & 2 & 2 & 51 \\
\hline $\begin{array}{c}\text { Brilho intenso } \\
\text { Contraste suave }\end{array}$ & 4 & 2 & 80 \\
\hline $\begin{array}{c}\text { Brilho suave } \\
\text { Contraste intenso }\end{array}$ & 2 & 4 & 75 \\
\hline
\end{tabular}

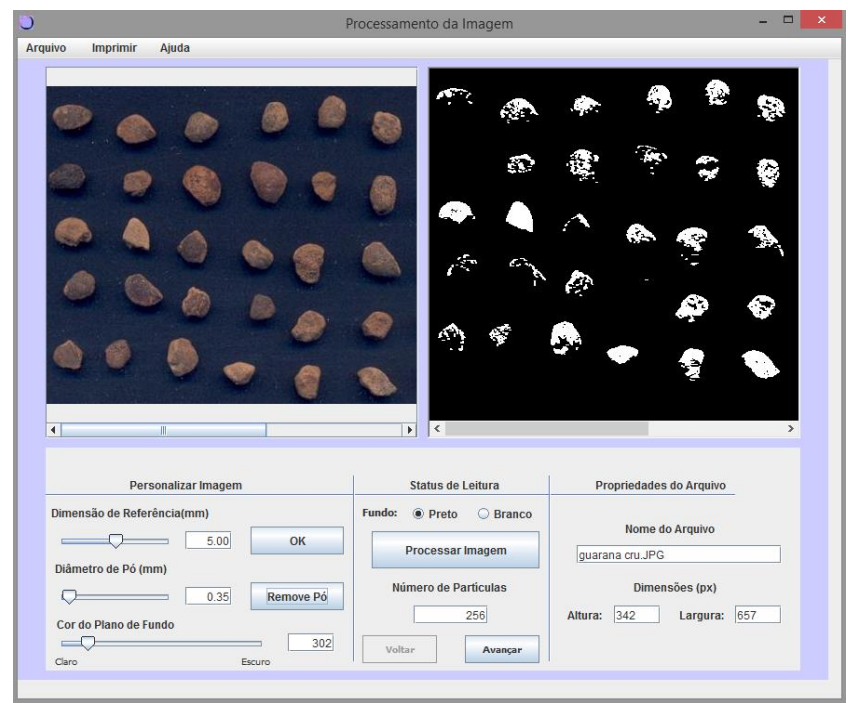

Figura 1: Processamento de 50 partículas

Além disso, a aplicação de referências (ex.: moedas de 1,0 real à 5 centavos) foram utilizados para equalizar os diâmetros das partículas ${ }^{[2]}$.

Por fim, foi elaborado um modelo Canvas de forma preliminar, funcionando como uma ferramenta estratégica para avaliar a viabilidade de produto no mercado. O software APOGEO expressa um apelo comercial para o ramo acadêmico e industrial.

\section{Conclusões}

O software APOGEO [2] apresenta uma solução eficiente, reproduzindo o dimensionamento e esfericidade de partículas sólidas para diversas geometrias e formatos desde que seja seguido um padrão de distribuição de cor da imagem processada. Além disto, o software apresenta a possibilidade de comercialização, pautado no modelo de negócio criado com base na metodologia Canvas.

\section{Agradecimentos}

Os autores agradecem ao CNPq pelo apoio financeiro.

1 LIMA-CORRÊA, R. A. B.; FREIRE, J. T.; FERREIRA, M. C. Caracterização de Meios Porosos Constituídos por Folhas de Manjericão (Ocimum basilicum L.). In: Anais do XX Congresso Brasileiro de Engenharia Química, v.1, n. 2, p. 6345-6352, 2015.

2 TANNOUS, K.; SILVA, F. S. Particles and Geometric Shapes Analyzer APOGEO. In: Mehdi Khosrow-Pour (Org.). Encyclopedia of Information Science and Technology, $3^{\circ}$ Edição. Hershey: IGI Global, v. V, p. 3568-3579, 2014 . 